\title{
Multiple Remote Tower for Single European Sky: the Evolution from Initial Operational Concept to Regulatory Approved Implementation
}

\author{
Peter Kearney ${ }^{1}$ and $*$ Wen-Chin $\mathrm{Li}^{2}$
}

\footnotetext{
${ }^{1}$ ATM Operations and Strategy, Irish Aviation Authority, 11-12 D'olier Street, Dublin, Ireland

${ }^{2}$ Safety and Accident Investigation Center, Cranfield University, Martell House, Cranfield, Bedfordshire, MK43 0TR, United Kingdom
}

\section{Corresponding author: Wen-Chin Li}

Postal Address: Safety and Accident Investigation Centre, Martell House, Cranfield University, Bedfordshire, MK43 0TR, United Kingdom

Tel: $+44(0) 1234758527$

E-mail: wenchin.li@cranfield.ac.uk

\section{Content of Manuscript}

Running Head: Multiple Remote Tower for Single European Sky

Manuscript Type: Research Article

Exact Word Count of Text: 7,707 words

Abstract: 298 words

Figures: 6

Tables: 7

References: 48

\section{Biographies of Authors}

Peter Kearney

Director of ATM Operations and Strategy, Irish Aviation Authority, Dublin, Ireland PhD Canadidate of Safety and Human Factors in Aviation, School of Engineering, Cranfield University, U.K.

\section{Wen-Chin Li PhD C.ErgHF}

Senior Lecturer, Safety and Accident Investigation Center, Cranfield University, United Kingdom

$\mathrm{PhD}$ in Aviation Human Factors, College of Aeronautics, Cranfield University, United Kingdom 


\begin{abstract}
The European Union project, Single European Sky, initiated a reorganization of European airspace and proposed additional measures for air traffic management to achieve the key objectives of improving efficiency and capacity while at the same time enhancing safety. The concept of multiple remote tower operation is that air traffic controllers (ATCOs) can control several airfields from a distant virtual control centre. The control of multiple airfields can be centralised to a virtual centre permitting the more efficient use of ATCO resources. This research was sponsored by the Single European Sky ATM Research Program and the ATM Operations Division of the Irish Aviation Authority. A safety case was developed for migration of multiple remote tower services to live operations. This research conducted 50 large scale demonstration trials of remote tower operations from single tower operations to multiple tower operations for safety assessment by air navigation safety regulators in 2016 . A dedicated team of air traffic controllers and technology experts successfully completed the safety assessment of multiple remote tower operations in real time. The air movement control and surface movement control at both Shannon and Cork airports were conducted simultaneously from a virtual remote tower centre at Dublin Airport, Ireland. The implementation of this innovative technology requires a careful balance between costefficiency and the safety of the air traffic control in terms of capacity and human performance. The live trial exercises demonstrated that the air traffic services provided by the remote tower for a single airport and two medium airports by a single ATCO with 'in sequence' and 'simultaneous' aircraft operations was at least as safe as provided by the local towers at Cork and Shannon aerodromes. No safety occurrence was reported nor did any operational safety issue arise during the conduct of the fifty live trial exercises.
\end{abstract}

Keywords: Air Traffic Control, Cost Efficiency, Human Performance, Multiple Remote Tower Operations, Safety Assessment, Single European Sky 


\section{Introduction}

The initial concept of remote tower operations was started by the research proposal of Virtual Control Tower over 20 years ago (Kraiss \& Kuhlen, 1996). The paradigm of remote tower operations will allow air traffic services (ATS) be delivered remotely without direct observation from a local tower. The emerging technology of remote towers developed slowly during the early stages but in recent times has taken a leap forward with some single airport virtual tower operations. SeaRidge technologies in partnership with HungaroControl have secured certification for the provision of remote tower live operations without restrictions; SAAB has provided London City airport with its digital tower platform to begin its landmark replacement of the conventional tower with remote solution. Norway's air navigation service provider Avinor has collaborated with Indra, Navia and Kongsberg to implement remote tower provision at up to fifteen low density airports from one central location (Otsby, 2016). Italian air navigation services providers ENAV successfully tested "Remote Airport Concept of Operation" (RACOON) which validated multiple mode operations at Milan Linate airport from Milan Malpensa (SESAR, 2016). Additionally, remote tower operations to medium size aerodromes were demonstrated by DFS at Saarbrücken Airport and by LVNL for Eelde Airport in active as well as in passive shadow mode based on operational procedures used in their respective conventional towers (SESAR, 2015a).

The development of Augmented Vision Video-panorama technologies has increased the monitoring capabilities of remote tower operations (RTO). Both monitoring and communication are important tasks of ATCOs, the concept of MRTO raised a safety concern of human performance in higher traffic environments (Papenfuss \& Friedrich, 2016). The identification of visual properties used by ATCOs to monitor aircraft for landing and manoeuvring at airports are critical to aviation safety. ATCO's use Out the Window visualisation (OTW) supported by radar data processing (RDP), electronic flight strips (EFS) and a communications network (TEL) to provide air traffic services in the airfield environment (Ellis \& Liston, 2016). It is likely that ATCOs' monitoring performance is influenced by the system design of remote tower centre (RTC) and the performance of multiple tasks simultaneously would require the sharing of cognitive resources of the controllers. The concept of distributed cognition seeks to understand the structure of cognitive system and extends the application to encompass interactions between resources and information in the operational environment (Hollan, Hutchins, \& Kirsh, 2000). The motivations of this research are to understand the limitations of controlling simultaneous traffic patterns at two airports by a single ATCO, to demonstrate how the implementation of 
the advanced technology impacts safety, capacity and human performance, and how to conduct safety assessment of MRTO in order to secure regulatory approval for live operations. Based on the concept of remote tower operations, multiple remote tower operations (MRTO) offer further solutions for cost efficiency of air traffic services for small and medium size of airports. The new technology will allow one air traffic controller (ATCO) control two or more airports at the same time during low traffic volumes. The feasibility of controlling two airports simulataneosuly was demonstrated successfully with a special focus on the visual attention of ATCOs and the controller working position design (CWP) related to ATS task (Moehlenbrink \& Papenfuss, 2011).

\section{Background of Policy and Practice}

This Multiple Remote Towers research was sponsored by the Single European Sky ATM Research Program (SESAR) and the ATM Operations Division of the Irish Aviation Authority. The Remote Tower Centre (RTC) was located at Dublin Air Traffic Services Unit in excess of 100 nautical miles away from the two airports at Shannon and Cork where the services were provided simultaneously (figure 1). Cork airport is a H24 international airport with aircraft types up to medium weight category such as Boeing 737 and Airbus 320. Total movements in 2016 were 50,242. Shannon is a H24 international airport with aircraft types up to the heavy weight category such as Airbus A330, it handled 25,059 movements in 2016. This research will contribute to the objectives for in sequence and simultaneous remote provision of ATS for multiple aerodromes as outlined in the Operational Improvement Step (OIS) SDM-0205 linked to SESAR Work Package (WP) 06.09.03 of the EU ATM Master Plan.

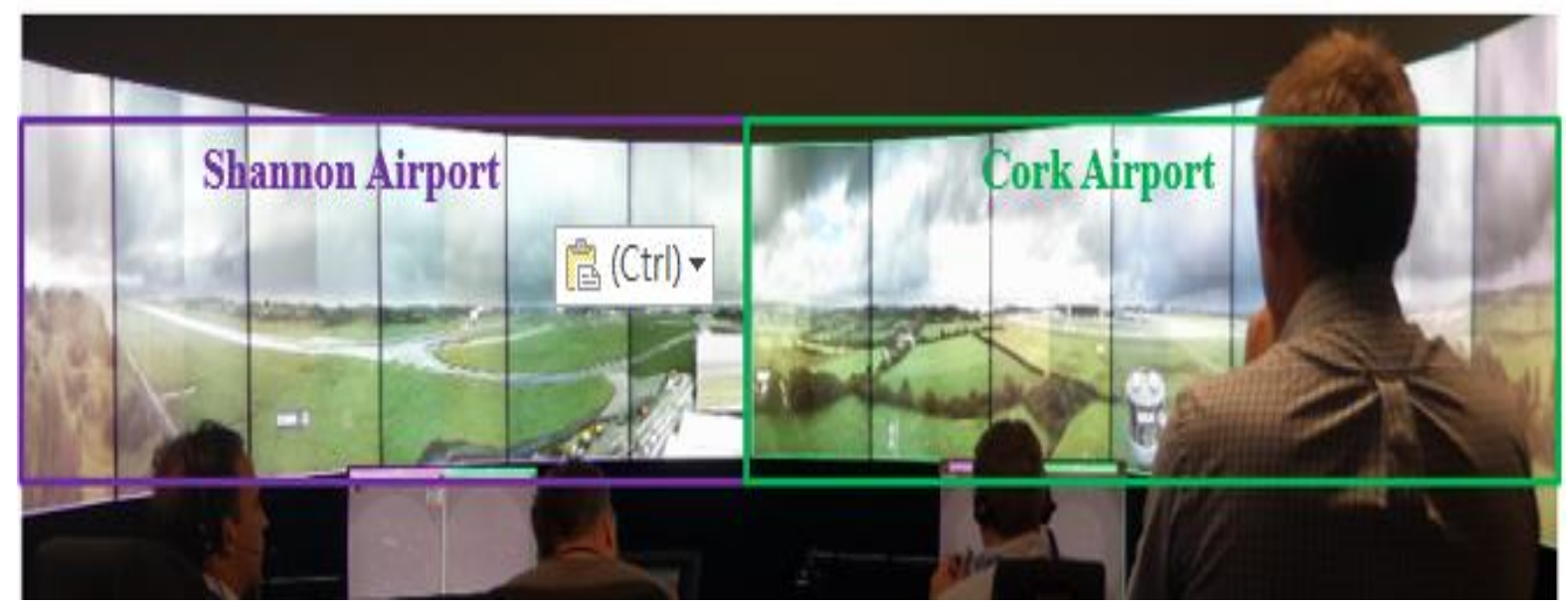


Figure 1. The Remote Tower Centre located at Dublin Airport in excess of 100 miles away provided air traffic services for both Cork and Shannon airports

\subsection{The Evolution of Remote Tower Operation}

Air traffic in Europe has consistently increased since the 1990s. The Single European Sky (SES) initiated a reorganization of European airspace based on traffic flows instead of national boundaries and proposed additional measures for air traffic management to achieve key objectives of enhanced efficiency and capacity while improving safety performance. SES regulations focussed on efficiency, capacity and safety have increased cost pressure on air navigation service providers and require them to be more innovative in their approach to the provision of air traffic management services. Many air navigation service providers (ANSPs) have developed automated systems using video-panorama cameras for synthetic outside view, to increase capacity at airports and to improve cost efficiency by minimising personnel to meet cost efficiency targets (Leitner \& Oehme, 2016). This has seen increased attention in remote tower research over the last 20 years. The concept of remote tower operations is that an ATCO can control any airfield from a distant virtual control centre. The view of the airfield under control is displayed in real time on screens and air traffic movements can be controlled. This concept is predominantly appropriate for the lower volume airports. Therefore, the control of multiple airfields can be centralised permitting capital and operational costs savings. Consequently, the visual features of cues and objects which ATCOs must identify for safe operations are significant influencers of the requirements for surveillance cameras, data-communication links and display systems in a remote tower centre (Van Schaik, Roessingh, Lindqvist, \& Falt, 2016). The concept of an advanced remote tower was developed for airports with fewer than 25 movements at the mean busy hours with a mix of visual flight rules and instrument flight rules. Technology advances can facilitate the image-video resolution for visual detection but not for recognition.

The German Aerospace Centre also has evaluated the metrics of aircraft on Dutch roll, Route, Decline, Landing light, Flight path and Gear status to evaluate the performance of ATCOs' visual identification by remote tower module. To test the feasibility of the RTO concept, V-2 feasibility of human-in-the-loop have been conducted and validated for single remote tower operations (Friedrich \& Mohlenbrink, 2013; Friedrich, 2016). NextGen is concerned with the diverse aspects of tower control including human-computer interaction, situation awareness, cost of airport control tower, safety management and capacity variation (Federal Aviation Administration, 2012). NASA has also examined remote tower operations by studying 
alternative approaches for improving runway safety at Los Angeles International Airport (LAX) under future flight central program (Dorighi \& Rabin, 2002). The preliminary research demonstrated that remote tower operations can provide substantial economic benefits compared to the traditional operations of local air traffic control towers, as NextGen proposed an innovative concept to address airport capacity problem by introducing an integrated tower information display providing weather and surveillance data as decision support tools (Nene, 2008). The concept of remote towers exhibited encouraging improvements in communications and departure rates with no differences in perceived workload, effort, safety and situation awareness (Nickelson, Jones, \& Zimmerman, 2011). This option may offer operational cost saving, and the level of services provided to pilots operating under visual flight rules might be reduced.

\subsection{The Cost Efficiency of Multiple Remote Tower Operation}

Multiple Remote Tower Operations is an alternative solution to enhance safety and capacity at small/medium airports in a cost efficient manner. This new technology allows one ATCO control one or more small airports from a remote location without direct visualization of the airport under their control (Fürstenau, 2016). Furthermore, the building and operational costs of remote tower facilities is much lower compared with a traditional physical tower. However, there is a trend of growing concern by safety regulators as to how human performance is managed using these new technologies. There is a requirement to develop a safety case and address concerns that multiple remote tower operations may increase operational risk for ATCOs (SESAR Joint Undertaking, 2013, 2015b).

Over $75 \%$ of regional airports with lower than one million passengers are currently making a loss. Cost of ATC services present the major portion of a regional airport's overall operating costs. The operational services of regional airports are similar, so the costs can be shared by relocation of the ATC function of two or more airports to a shared facility of multiple remote tower centre. The introduction of multiple remote tower operations is mainly driven by a desire reduce ATS operational costs in order to meet Single European Sky cost reduction requirements. However, the SESAR assessment report of remote tower for multiple airports added additional safety specifications as requirements (Ziegler, 2016). IAA has conducted an analysis of the total costs of building and operating a physical tower by compared with the costs of remote tower. The result demonstrated that remote tower operations reduces costs significantly on the buildings, infrastructure and operational manpower in the order of $€ 1.3$ 
million per year (table 1). Furthermore, Federal Aviation Administration (2012) revealed that the construction of a single control tower under federal contract might take three to five years with approximately $\$ 4.2$ million plus the average annual operational costs and maintenance costs of $\$ 185,000$ and several hundred thousand dollars for annual controllers' compensation.

Table 1: The comparison of cost-efficiency between existing tower and remote tower

\begin{tabular}{|c|c|c|c|}
\hline & Build & Equipment & Manpower \\
\hline $\begin{array}{l}\text { Traditional } \\
\text { Tower }\end{array}$ & $\begin{array}{l}\text { Roughly cost } £ 12 \mathrm{M} \text { to Build. } \\
\text { To assume } 10 \% \text { annual running } \\
\text { cost for the building is } \\
\text { reasonable } £ 1.2 \mathrm{M} \text { a year. }\end{array}$ & $\begin{array}{l}\text { Usual Communications, } \\
\text { Navigation, Surveillance and } \\
\text { Flight Data Processing } \\
\text { Systems. }\end{array}$ & $\begin{array}{l}\text { Typical manning is } 8 \text { to } 10 \\
\text { staff per H24 position. }\end{array}$ \\
\hline $\begin{array}{l}\text { Remote } \\
\text { Tower }\end{array}$ & $\begin{array}{l}\text { Build costs will reduce } \\
\text { significantly as only a mast } \\
\text { needed to house the cameras. } \\
\text { Estimated cost of mast } £ 2 \mathrm{M} \\
\text { saving } £ 10 \mathrm{M} \text {. } \\
\text { To assume } 10 \% \text { annual running } \\
\text { cost for the Mast is reasonable } \\
\text { e.g. } £ 200 \mathrm{~K} \text { a year saving } \\
£ 800 \mathrm{~K} \text { a year. } \\
\text { In summary if the tower is } \\
\text { depreciated over } 30 \text { years, } \\
\text { saving is }(12-2) / 30=£ 333 \mathrm{~K} \text { in } \\
\text { CAPEX, plus } £ 800 \mathrm{~K} \text { in OPEX } \\
\text { so } £ 1.33 \mathrm{M} \text { a year. }\end{array}$ & $\begin{array}{l}\text { Additional CAPEX is } £ 2 \mathrm{M} \text {. If } \\
\text { the remote tower system is } \\
\text { depreciated over } 8 \text { years, } \\
\text { additional costs is } 2 / 8=£ 250 \mathrm{~K} \\
\text { in CAPEX, plus } £ 200 \mathrm{~K} \text { in } \\
\text { OPEX so } £ 450 \mathrm{~K} \text { a year. } \\
\text { There should be potential to } \\
\text { save on some of the } \\
\text { Communications, Navigation, } \\
\text { Surveillance and Flight Data } \\
\text { Processing Systems Costs via } \\
\text { centralisation which will offset } \\
\text { some of the increase in network } \\
\text { costs. }\end{array}$ & $\begin{array}{l}\text { Remote Towers will facilitate } \\
\text { staffing efficiencies. The } \\
\text { objective is to crew to } \\
\text { workload such that } \\
\text { operational staff are always } \\
\text { busy within allowable safety } \\
\text { limits. } \\
\text { For the IAA example of Cork } \\
\text { and Shannon controlled from } \\
\text { Dublin we anticipated a } \\
\text { saving of } 4 \text { ATCO's or } \\
£ 400 \text { K a year. }\end{array}$ \\
\hline
\end{tabular}

\subsection{Safety Assessment of Multiple Remote Tower Operations}

The Safety Assessment Report for Multiple Remote Towers (SESAR Joint Undertaking, 2015b) contemplated the availability of surveillance data to support ATCOs task performance in bad weather conditions (Ziegler, 2016). The IAA ANSP as sponsor and project coordinator is the ANS provider for Dublin, Cork and Shannon airports. The Dublin Airport Authority (DAA) as the airport operator for Cork Airport and Stobart Air are an international commuter airline. The Shannon Airport Authority (SAA) was involved as a stakeholder. A Demonstration Plan was prepared to describe how the live trial exercises would be organised, conducted, supervised, and assessed. This plan focused on safety, capacity, cost efficiency and human performance concerns. The safety case report is a structured argument, supported by a body of evidence that provides a compelling, comprehensible and valid case that a system is safe for a given application in a given environment. It provides a comprehensive 
and structured set of safety documentation which is aimed to ensure that the safety of a specific system or equipment is safe for operational deployment. It will also establish the requirements for safety monitoring following transition into operation and for the entire life cycle of the system through to decommissioning (European Aviation Safety Agency, 2014, 2015b).

For delivery of a safety argument for approval the IAA project team developed a "safety case" by applying the Eurocontrol safety assessment methodology (SAM) to provide safety assurance that the introduction of any new technological systems or changes to these systems are proven to be tolerably safe for service provision. The safety assessment methodology of current research follows a structured step wise process as followings (figure 2);

(1) Safety Plan defines a safety programme that is planned, integrated and developed in conjunction with other design, development, production and quality control activities. It details safety activity timelines and deliverable in accordance with the higher project plan. It requires regulatory endorsement and approval.

(2) Functional Hazard Assessment (FHA) records the functions to be performed by the system, the effects of identified hazards on operations, including assessment of the severity of the hazards effects and also records the derived safety objectives, i.e. determines their acceptability in terms of the hazards maximum frequency of occurrence, derived from the maximum frequency of the hazards effects.

(3) Preliminary System Safety Assessment (PSSA) produces Safety Requirements and Assurance Levels for the system elements and records the evidence, arguments and assumptions to verify that the proposed solution will meet its Safety Requirements. It also provides the arguments to support the claim that the system will not affect the safety of the ATM system during installation and commissioning.

(4) System Safety Assessment (SSA) records the evidence, arguments and assumptions to verify and validate that the system design configuration will meet its Safety Requirements. It also describes specific operating and maintenance requirements necessary to assure safety and provides arguments to support the claim that the system will not affect the safety of ATM during the transition to operational use. In addition, the SSA provides details of the Transition Plan for introducing the system into service. 


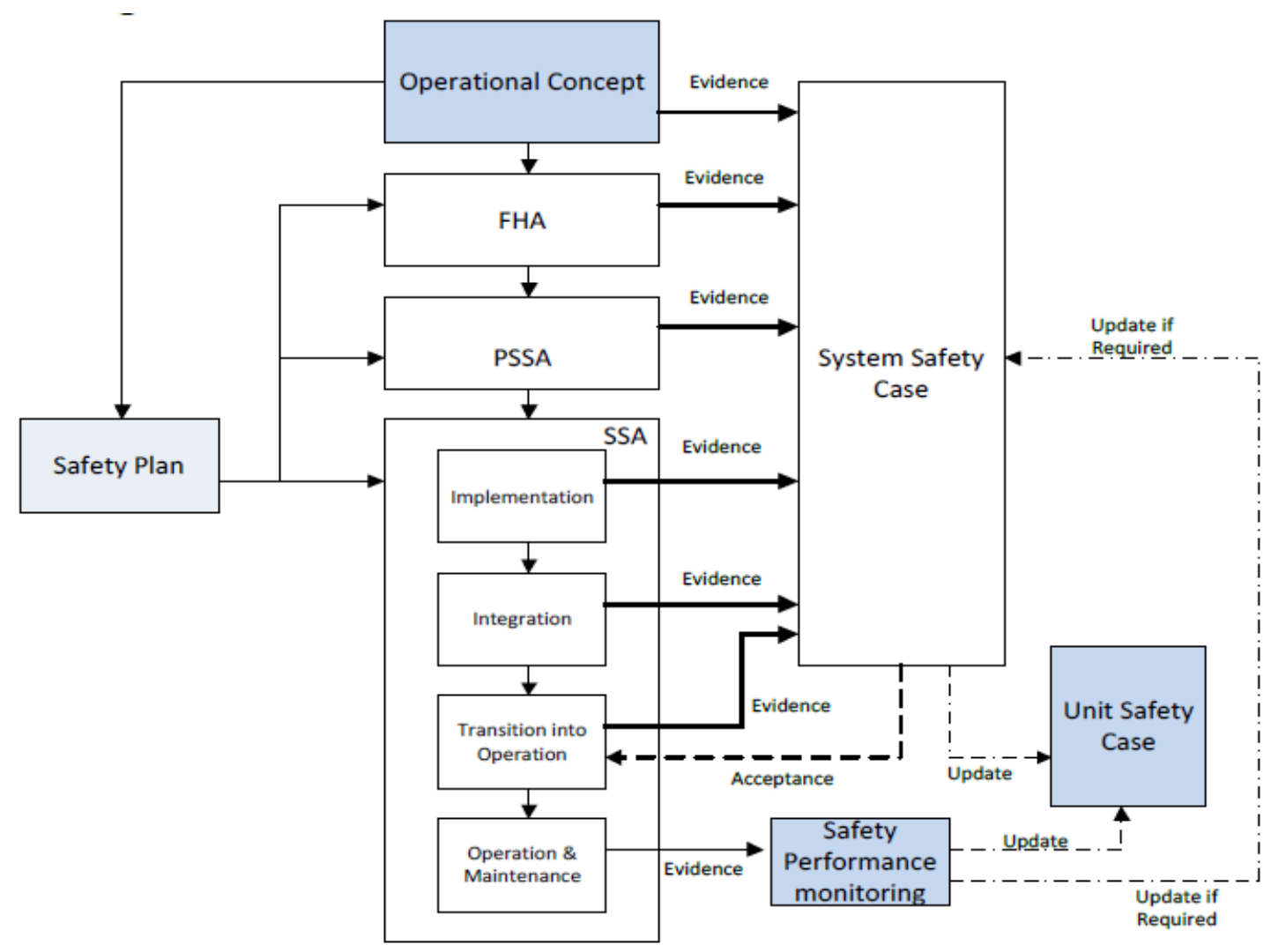

Figure 2. Safety assessment Methodology applied by IAA Terminal Services

\subsection{The Processes of Regulatory Approval for Practical Implementation}

The regulatory body responsible for the regulation of aviation in Europe is the European Aviation Safety Agency (EASA) based in Cologne, Germany with offices in Brussels. It has been providing safety regulation for member states in Europe since 2002. It is an agent of the European Union, its mission is to ensure the highest common level of safety protection in aviation for EU citizens. EC Regulation 549 /2004 'The Article-4 of Framework Regulation mandates that each European Communities State establish a National Supervisory Authority (NSA) with responsibilities for the supervision and safety oversight of Air Navigation Service Providers which provide air traffic control, airspace management and air traffic flow management services (Pellegrini \& Rodriguez, 2013). The Irish Department of Transport (DoT) have designated the Safety Regulation Division (SRD) of the Irish Aviation Authority as the NSA for Ireland with Aeronautical Services Department (ASD) specifically charged with the oversight of all ANSP's nationally. External oversight of the IAA is carried out by two independent bodies, namely; the International Civil Aviation Organisation (ICAO) a body of the United Nations (UN), who conduct safety oversight audits of all States' safety 
regulation authorities worldwide and EASA, who routinely audit the IAA regulatory Body. In accordance with internal ANSP safety processes the safety case report was submitted to its safety management unit (SMU) to ensure all evidence and arguments were met and that all identified hazards and their subsequent effects were assessed, documented and safety requirements implemented prior to operational usage of the multiple remote tower concept. Any open issues were highlighted and detailed in the safety case report ahead of the trial being conducted. During the trial, safety levels were monitored by the implementation of a shadow operation whereby the actual towers of Cork and Shannon were manned by appropriately qualified and competent controllers while service delivery was being provided from Dublin RTC (European Aviation Safety Agency, 2014; SESAR Joint Undertaking, 2015b).

Safety Regulatory approval would be dependent upon the provision of evidence of in service trials which, this evidence was collected through the deployment of large scale demonstration (LSD) trials of remote tower operations for multiple airports. These involved the provision of air traffic services at two airports at the same time utilising innovative technological solutions. A dedicated team of operations and technology experts completed 50 trials demonstrating multiple remote tower operations in real time, specifically, air movement control (AMC) and surface movement control (SMC) at Shannon and Cork airports simultaneously from the remote tower centre at Dublin Airport. Trials were only permitted following the submission of a detailed and comprehensive safety argument, submitted by Terminal Services Operations (European Aviation Safety Agency, 2015a; SESAR Joint Undertaking, 2013) to the Irish National Supervisory Authority.

\section{Methodology of Large Scale Demonstration}

The large scale demonstration of multiple remote tower operations was provided in sequence or simultaneously for both Cork and Shannon airports during periods of low traffic density building on the SESAR solution package for remote tower for single and multiple airports. Out the window visualisation supported by radar and electronic strip technology and the existing data and communications network will provide the necessary environment for the provision of ATS remotely and without degradation. The project was supported by a safety case which was approved by the NSA for Ireland. Fifty live trial exercises involving up to 500 aircraft were conducted between June and September 2016.

\subsection{Participants}


Three qualified and licensed air traffic controllers holding appropriate ratings on both Cork and Shannon airports participated in the live trial demonstrations in accordance with (EU) 805/2011 and EASA NPA 2015-04. SAAB systems provided familiarisation and HMI training on the RTC CWP and ATCOs were certificated accordingly. Train the trainer certificates were granted to specialists in IAA. This training combined in conjunction with the training specified in all relevant aspects of the RTC including the electronic strip system continued up to the demonstration commencement date. The approval of Science and Engineering Research Ethics Committee was granted (CURES/1506/2016) in advance of the research taking place.

\subsection{Apparatus}

3.2.1 Remote Tower Module (RTM): This project applied Saab's remote tower systems consisting of a camera array, pan/tilt/zoom (PTZ) cameras and signal light guns (SLG) at Cork and Shannon airports controlled from a Remote Tower Centre (RTC) at Dublin ATS unit. The RTC is provided with Out the Window visualisation (OTW), Electronic Flight Strip (EFS) System and an air/ground and ground/ground voice communication system (TEL) for the appropriate Cork and Shannon VHF frequencies and sector coordination function respectively (Figure 3). The RTC contained two panoramic OTW display comprised by 15 full HD LED display screens (14 active \& 1 spare) which provide a panoramic 360 degree view of the selected airport and its surrounding airspace in a 208 degree configuration. Therefore, one ATCO could provide services for both Cork and Shannon using one OTW display.
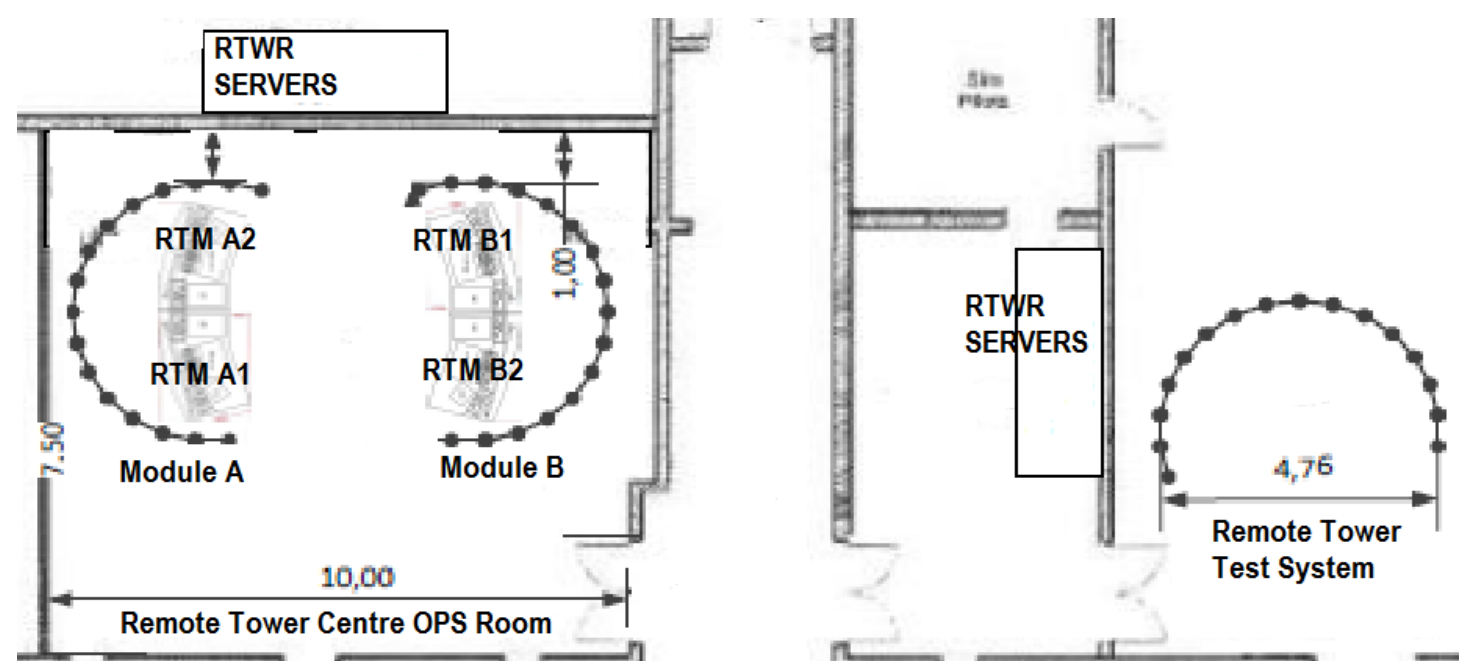

Figure 3. Remote Tower Centre OPS Room and Test \& Validation Room 
The OTW displays are normally used to present the images from the 14 cameras, while the last display is a stand-by unit in the event of equipment failure. The displays match the camera resolution of 1920x1080 pixels, and have a refresh rate of at least $60 \mathrm{~Hz}$. The displays are mounted in portrait mode to match the portrait-mounted cameras. The PTZ cameras controlled from RTC allow the ATCO a 30 times zoom (optical), 90 degrees up and 80 degrees down tilt, panning 360 degrees and selection of pre-defined sweeps and/or positions. The PTZ view is displayed on the OTW display (Figure 4). Each RTM is equipped with the Saab's e-Strip which consists of a top bar, a vehicle map, a strip board and a bottom bar. The top bar contains a settings dialogs for changing role and runway combination, as well as certain status information. The top bar also contains two buttons that will open side windows which are toolboxes from where new strips can be created and old strips can be recovered. The bottom bar contains a slider for adjusting the screen brightness. A vehicle map displays a graphical view of the runway and taxiway. Vehicles can be added, removed to/from the vehicle map or moved within the vehicle map. The radar target tracking presents information from the radar display as an overlay in the visual presentation, linked with the visual tracking. This enables the aircraft to be tracked with label attached providing radar information including call sign and altitude providing additional support to visual observation. The Flight Data Processing (FDP) includes the display of messages accessed by a pull down display on top of the visualisation display. Data displayed includes Flight Plan information and NOTAMS.

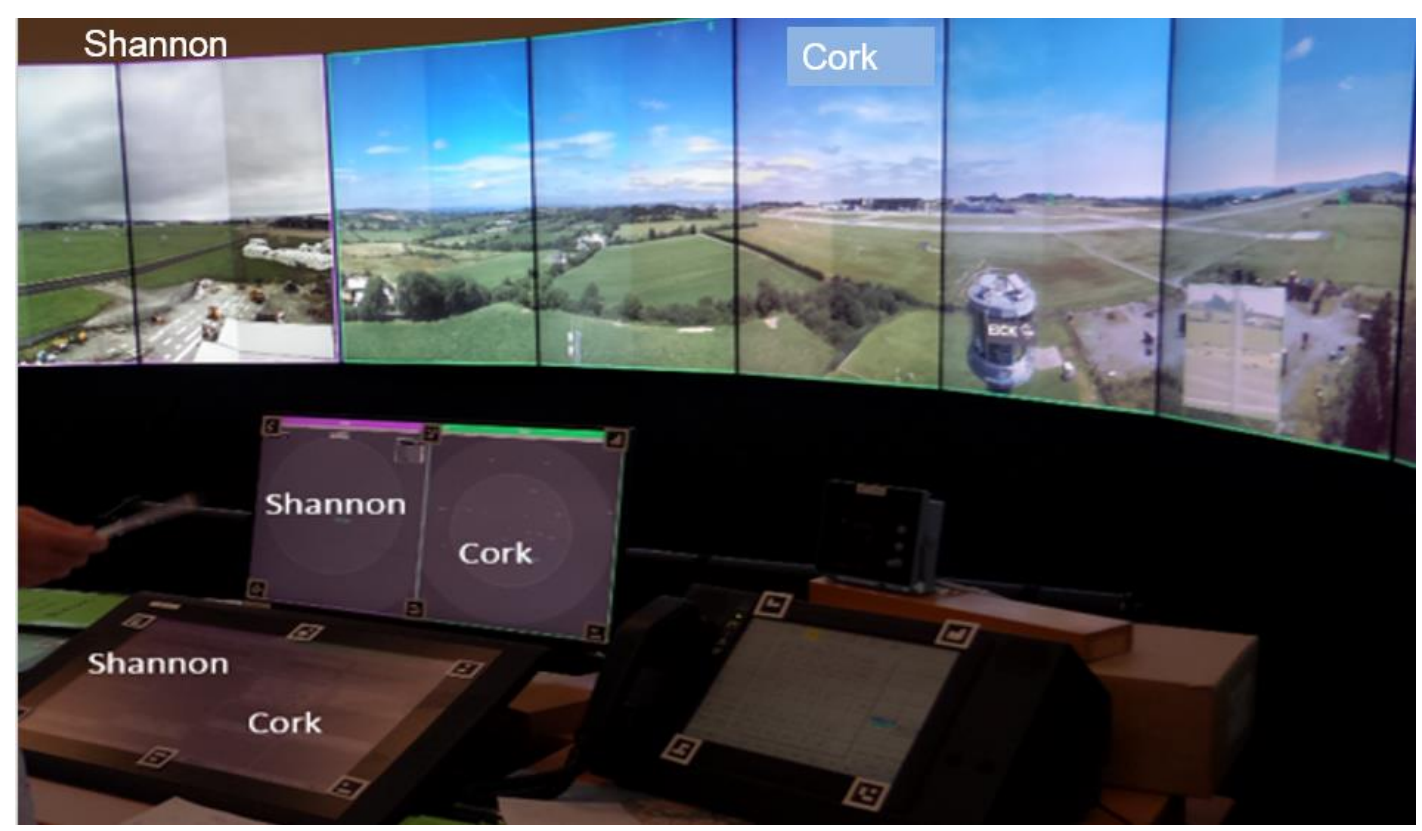


Figure 4. Controller Working Position (CWP) and Out of the Windows (OTW) screens of Remote Tower Module in RTC

3.2.2 Eye Tracking Device: The device of collecting ATCOs' visual behaviours is a light, mobile, head-mounted eye tracker developed by Pupil Lab. It allows participants to freely move their head and is composed of two cameras, one focused on the pupil and the other one the environment. Both cameras can be moved to accurately get eye detection and the pilot field of vision. The software used to record data is Pupil Capture 9.3 and the one used to process data is Pupil Player 9.3, both from the same company as the headset. The set-up of the eye camera is a $640 \times 480$ resolution for a 60 frames rate. The world camera is a $1280 \times 720$ with a frame rate of 30 , however due to computer limitation, this frame rate can be flexible due to the volume of data processing and is not constant over time. The cameras are adjustable to suit different participant's facial layout and track their pupil parameters accordingly (Kassner, Patera, \& Bulling, 2014).

\subsection{Safety Case for 50 Live Exercises}

The Safety Case for multiple remote tower live trials followed the SESAR standard four-part safety case approach beginning with the production of a safety plan. This framework outlines the safety case activities to be conducted for the entire Remote Tower System (people, procedures, and equipment), the specific deliverables applicable and the timescale for submission to the NSA. This was followed by the production of a functional hazard analysis which formed the basis for the setting of safety objectives and requirements for the system. A preliminary system safety assessment document was then developed leading to a final system safety assessment. Each deliverable was submitted to the NSA as it reached maturity. A hazard log was also developed which remained open for the duration of 50 live exercises so that any previously unidentified hazards could be recorded and mitigated appropriately.

General requirements regarding traffic scenarios were defined in the demonstration plan as well as the selection of Cork and Shannon airports. Traffic parameters such as traffic flows, depart/arrival ratio, visual flight/instrumental flights are realistic at both airports. The demonstration plan also described the success criteria for each live exercise and how the 50 live exercises were further divided into three batches. The first batch of exercises (numbers 1 to 5) had the objective of familiarising operational and technical personnel with the procedures to be used, and the environment in which they will be operating for SMC (table 2). The second batch of exercises (numbers 6 to 20) had the objective of demonstrating the applicability of integrated SMC and AMC operations with incrementally increased traffic 
movements mixing arrivals and departures at both Cork and Shannon airports. Flexibility in the timing of exercises was applied to maximise the variability of scenarios to be used with regard to runway in use, type of approach (instrument or visual). During this phase the simultaneous scenario (Cork and Shannon) was introduced with low traffic movements (table 3). A further 30 exercises (numbers 21 to 50) were conducted with the objective of building on the experience gained from previous exercises with increased traffic movements as appropriate in the sequenced and simultaneous scenarios (table 4).

Table 2: The description of batch-1 live exercises 1-5

\begin{tabular}{|c|l|}
\hline $\begin{array}{c}\text { Exercise } \\
\text { Id }\end{array}$ & \multicolumn{1}{|c|}{ Exercise Description } \\
\hline 001 & Shannon (SNN) SMC only in Module RTM-A1 \\
\hline 002 & Cork (CRK) SMC only in Module RTM-A2 \\
\hline 003 & Control of SNN SMC in RTM-A1 \& Cork SMC in RTM-A2 \\
\hline 004 & CRK SMC first then SNN SMC combined on a single position \\
\hline 005 & $\begin{array}{l}\text { CRK SMC in RTWR A2 SNN SMC in RTWR 1 with different screen configuration to } \\
\text { exercise 003 }\end{array}$ \\
\hline
\end{tabular}

Table 3: The description of batch-1 live exercises 6-20

\begin{tabular}{|c|l|}
\hline $\begin{array}{c}\text { Exercise } \\
\text { Id }\end{array}$ & \multicolumn{1}{c|}{ Exercise Description } \\
\hline 006 & Control of SNN SMC in RTM-A1 \& Cork SMC in RTM-A2 \\
\hline 007 & Control of SNN SMC \& SNN AMC from a single position in RTM-A1. No Cork Positions. \\
\hline 008 & Control of SNN AMC \& SNN SMC in RTM-A1 and Cork SMC in RTM-A2 \\
\hline 009 & Continuation of exercise 08. Hand back CRK and split SNN SMC onto RTM-A2 \\
\hline 010 & Control of SMC \& AMC from a single position RTM-A1. \\
\hline 011 & Control of SNN AMC in RTM-A1. Cork AMC in RTM-A2 \\
\hline 012 & $\begin{array}{l}\text { Merge SNN AMC and Cork AMC in RTM-A2 This exercise is a continuation of exercise 11 } \\
\text { whereby we kept control of both SNN \& CRK AMC Roles but merged them onto a single } \\
\text { position thereby making this exercise the first time Multiple AMC Control was performed } \\
\text { from a single Remote Tower position. }\end{array}$ \\
\hline 013 & $\begin{array}{l}\text { Control of SNN AMC in RTM-A1 and CRK AMC in RTM-A2 } \\
\text { The plan is to merge the two positions as soon as traffic allows }\end{array}$ \\
\hline 014 & $\begin{array}{l}\text { Control of SNN AMC in RTM-A1. Cork AMC in RTM-A2. } \\
\text { Control of SNN AMC in RTM-A1. CRK AMC in RTM-A2 } \\
\text { Later SNN and CRK AMC combined in RTM-A2 }\end{array}$ \\
\hline 015 & $\begin{array}{l}\text { Control of SNN AMC RTM-A1 CRK AMC RTM-A2 } \\
\text { Later SNN \& CRK AMC combined in RTM-A1 }\end{array}$ \\
\hline 016 & $\begin{array}{l}\text { Control of SNN AMC in RTM-A1. CRK AMC in RTM-A2 } \\
\text { Later SNN \& CRK AMC combined in RTM-A2 }\end{array}$ \\
\hline 018 & Control of SNN AMC in RTM-A1. CRK AMC in RTM-A2. \\
\hline 019 & Control of SNN \& CRK AMC combined in RTM-A2 \\
\hline 020 & $\begin{array}{l}\text { Control of SHA AMC in RTM-A1. No Control of CRK AMC due to Low visibility in Cork } \\
\text { which needed to be aware before actively Controlling in these conditions. }\end{array}$ \\
\hline
\end{tabular}




\begin{tabular}{|c|c|}
\hline $\begin{array}{l}\text { Exercise } \\
\text { Id }\end{array}$ & Exercise Description \\
\hline 021 & $\begin{array}{l}\text { Control of SNN AMC in RTM-A1. CRK AMC in RTM-A2 initially then later in the exercise } \\
\text { SNN \& CRK AMC combined in RTM-A2 }\end{array}$ \\
\hline 022 & $\begin{array}{l}\text { Control of SNN AMC in RTM-A1 CRK AMC in RTM-A2 initially then later in the exercise } \\
\text { SNN \& CRK AMC combined in RTM-A2 }\end{array}$ \\
\hline 023 & Control of SNN \& CRK AMC combined in RTMA1 \\
\hline 024 & $\begin{array}{l}\text { Control of SNN AMC in RTM-A1 CRK AMC in RTM-A2 } \\
\text { Later SNN \& CRK AMC combined in RTM-A2 }\end{array}$ \\
\hline 025 & Continuation of exercise 024 . Control of SNN \& CRK AMC combined in RTM-A2 \\
\hline 026 & $\begin{array}{l}\text { Control of SNN AMC in RTM-A1 CRK AMC in RTM-A2 initially then later in the exercise } \\
\text { SNN \& CRK AMC combined in RTM-A2 }\end{array}$ \\
\hline 027 & $\begin{array}{l}\text { Control of SNN AMC in RTM-A1 CRK AMC in RTM-A2 initially then later in the exercise } \\
\text { SNN \& CRK AMC combined in RTM-A2 }\end{array}$ \\
\hline 028 & Control of SNN \& CRK AMC combined in RTM-A2 \\
\hline 029 & Control of SNN \& CRK AMC combined in RTM-A2 \\
\hline 030 & Control of SNN \& CRK AMC combined in RTM-A2 \\
\hline 031 & Control of SNN \& CRK AMC combined in RTM-A2 \\
\hline 032 & $\begin{array}{l}\text { Control of SNN \& CRK AMC combined in RTM-A1 } \\
\text { Control of SNN \& CRK SMC combined in RTM-A2 initially then later in the exercise Control } \\
\text { of SNN \& CRK AMC \& SMC combined in RTM-A2 }\end{array}$ \\
\hline 033 & $\begin{array}{l}\text { Control of SNN AMC in RTM-A1. CRK AMC in RTM-A2 initially then later in the exercise } \\
\text { SNN and CRK AMC combined in RTM-A2 }\end{array}$ \\
\hline 034 & Control of SNN \& CRK AMC combined in RTM-A2 \\
\hline 035 & $\begin{array}{l}\text { Control of SNN AMC in RTM-A1 CRK AMC in RTM-A2 initially then later in the exercise } \\
\text { SNN \& CRK AMC combined in RTM-A2 }\end{array}$ \\
\hline 036 & $\begin{array}{l}\text { Control of SNN AMC\& SMC in RTM-B2 } \\
\text { Control of CRK AMC\& SMC in RTM-A2 }\end{array}$ \\
\hline 037 & Control of SNN \& CRK AMC \& SMC combined in RTM-A2 \\
\hline 038 & $\begin{array}{l}\text { Control of SNN AMC in RTM-A1, then Control of SNN SMC in RTM-A2 } \\
\text { Next series of exercises is to follow the progression of workload starting with } 2 \text { Controllers at } \\
\text { one airport and in the next exercise moving to } 1 \text { Controller per airport. }\end{array}$ \\
\hline 039 & $\begin{array}{l}\text { Control of SNN AMC\& SMC in RTM-B2 } \\
\text { Control of CRK AMC\& SMC in RTM-A2 }\end{array}$ \\
\hline 040 & Control of SNN \& CRK AMC \& SMC combined in RTM-A2 \\
\hline 041 & Control of SNN \& CRK AMC \& SMC combined in RTM-A2 \\
\hline 042 & Control of CRK SMC in RTM-A1 \& CRK AMC in RTM-A2 \\
\hline 043 & Control of SNN SMC in RTM-A1 SNN AMC in RTM-A2 \\
\hline 044 & Control of SNN and CRK AMC combined in RTM-A2 \\
\hline 045 & Control of SNN and CRK AMC combined in RTM-A2 \\
\hline 046 & Continuation of Ex.45 Control of SNN and CRK AMC combined in RTM-A2 \\
\hline 047 & Control of SNN and CRK AMC combined in RTM-A2 \\
\hline 048 & Control of SNN and CRK AMC combined in RTM-A2 \\
\hline 049 & $\begin{array}{l}\text { Control of SNN AMC on RTA } 1 \text { and CRK AMC combined in RTM-A2 initially then later in } \\
\text { the exercise Control of SNN \& CRK AMC \& SMC combined in RTM-A2 }\end{array}$ \\
\hline 050 & Control of SNN \& CRK AMC \& SMC combined in RTM-A2 \\
\hline
\end{tabular}

\subsection{Procedures of Exercise Implementation}

IAA normal operational practice if to apply fully redundant systems and data lines for standalone operations (figure 5). This required a procedure commencing 20 minutes before transfer of Control from the local tower to the remote tower module and involved ATCOs cross checking information from Local Tower aircraft information strips against information on 
electronic strips at the RTM. This was initiated and completed through a phone call from the Remote Tower. The cross check also permitted the co-ordination of information on aircraft stand allocations, transponder codes and any upcoming local training details by training school aircraft on Cork airport. These cross checks were followed by a detailed handover of position(s) to the Remote Tower ATCO in accordance with current IAA operational position handover procedures including briefing on the current weather data, airfield lighting status and nav-aid status (10 Minutes before transfer of Control). Main air traffic control radio frequencies were deselected on the COMPAD communications system in the local tower who then temporarily reverted to operations via the Radio Backup System. This was to avoid simultaneous transmissions from two locations on a single transmitter which may cause transmitter failure.

A project consortium was established to ensure all aspects of relevant aviation activity was represented in the project. The project team consisted of Project Manager, an ATM Specialist, a Human Factors Expert and two appropriately rated Controllers who were present for the live trials. During the trials the following types of information was collected: (1) Exercise date and time; (2) Tower roles assumed in the RTC; (3) Exercise participants; (4) Weather at both airports; (5) Aircraft involved in each exercise and the timing (to the second) of events to record what actions a controller was conducting during each minute; (6) collecting ATCOs' eye movements and the debrief observations; (7) Aircraft involved in the exercise as well as recording notes on non-normal aircraft movements e.g. simulated engine failure or touch $\&$ go; (8) Completing the initial assessment of the controller impression of various aspects; (9) Compiling unexpected behaviour/results and recommendations. 


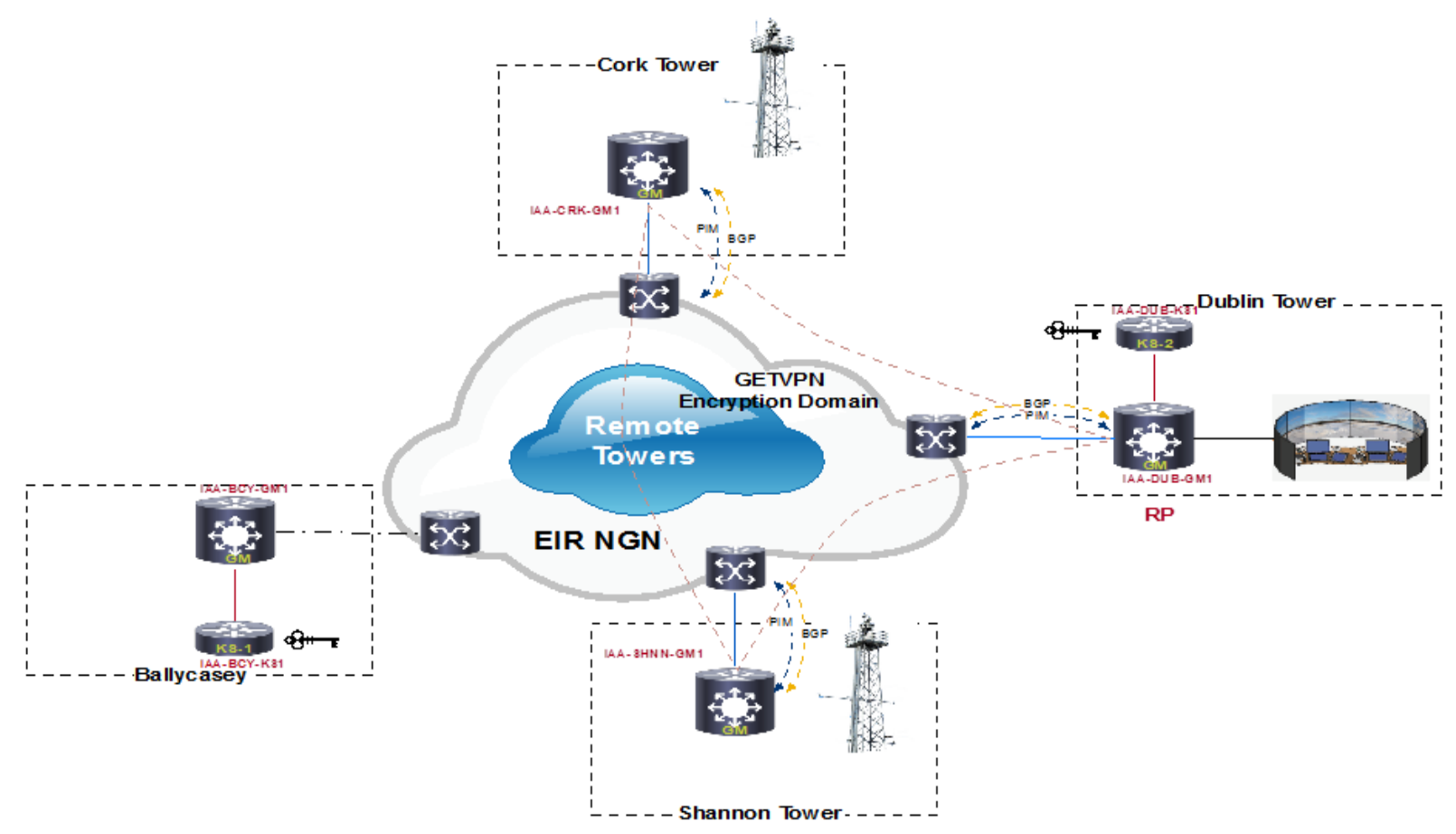

Figure 5. Video-Data Communications Links of Multiple Remote Towers Protected by IPsec for Data Confidentiality, Integrity and Authentication between Participating Peers

\section{Results of Large Scale Demonstrations}

The results of this research demonstrate that advanced remote technology based on humancentered design has improved ATCO's performance in monitoring and controlling more aircraft from two different airports. OTW design permits the adjustment of the percentage of the selected airports on the screens based on ATCO's preference, but they are also able to zoom-in by PTZ to enhance visual searching. Furthermore, OTW allows different colours to distinguish different airports, in this case green for Cork and red for Shannon, further increasing ATCO's situation awareness to which airport he/she is engaging. The EFS system integrates aircraft strip information with the map of runway and taxiway, providing the ATCO a clear picture of the locations of the moving targets. If an ATCO has permitted one aircraft to enter a runway, he/she will not be able to permit another aircraft moving to enter the same runway with this EFS. This is a very effective design to prevent runway incursions. The information presented by the RDP can facilitate ATCO in predicting the flow of traffic and landing time at each airport, thereby facilitating enhanced decision making in respect of simultaneous movements at both airports.

\subsection{Eye Scan Patterns of Single ATCO Performing Multiple Operations}


ATCOs' eye movements across four areas of interests (AOIs) including RDP, EFS, TEL and OTW were analysed while performing multiple tasks. A series of ANOVAs with four AOIs (RDP, EFS, TEL, and OTW) to assess single ATCO's eye movement patterns on multiple remote tower operations. The response variables are fixation count (FC), fixation duration (FD), saccade amplitude (SA), and pupil size (PS) shown as table 5.

4.1.1 Fixation duration: The assumption of sphericity is violated (Mauchly's $\mathrm{W}=.380, \mathrm{p}$ $<.001$ ), therefore the Greenhouse-Geisser is applied to adjust the univariate test. Results indicated no significant main effect of AOIs, $F(1.843,60.823)=2.192, p>.05$.

4.1.2 Fixation count: The assumption of sphericity is violated (Mauchly's $\mathrm{W}=.682, \mathrm{p}$ $<.05)$, therefore the Greenhouse-Geisser is applied to adjust the univariate test. A significant main effect of AOIs, F $(2.511,85.373)=22.385, \mathrm{p}<.001, \eta_{p}^{2}=.397$ was found. Post-hoc comparison on AOI revealed RDP is larger than EFS and TEL (ps <.001). Moreover, OTW is smaller than EFS $(\mathrm{p}<.001)$ and TEL $(\mathrm{p}<.001)$.

4.1.3 Saccade amplitude: The assumption of sphericity is not violated (Mauchly's $\mathrm{W}=.966$, $\mathrm{p}>.05)$, therefore no adjustment is required for the univariate test. A significant main effect of AOIs, $\mathrm{F}(3,87)=30.346, \mathrm{p}<.001, \eta_{p}^{2}=.511$ was found. Post-hoc comparison on AOI revealed OTW is larger than RDP, EFS, and TEL (ps $<.001$ ).

4.1.4 Pupil size: The assumption of sphericity is violated (Mauchly's $\mathrm{W}=.377, \mathrm{p}<.001$ ), therefore the Greenhouse-Geisser is applied to adjust the univariate test. A significant main effect of AOIs, F $(2.040,67.330)=11.687, \mathrm{p}<.001, \eta_{p}^{2}=.262$ was found. Post-hoc comparison on AOI revealed RDP is larger than EFS $(\mathrm{p}<.001)$. Moreover, TEL is larger than EFS $(\mathrm{p}<.001)$ and OTW $(\mathrm{p}<.001)$.

Table 5. Descriptive statistics of mean and standard deviation of four eye movement parameters among four AOIs

\begin{tabular}{cccccc}
\hline Tasks & Visual & FC & FD & SA & PS \\
& Parameters & $\mathrm{N}=35$ & $\mathrm{~N}=34$ & $\mathrm{~N}=30$ & $\mathrm{~N}=34$ \\
\hline \multirow{4}{*}{ RDP } & $46.74(25.036)$ & $.269(.069)$ & $55.461(30.958)$ & $81.460(7.500)$ \\
\cline { 2 - 6 } & EFS & $21.40(16.784)$ & $.232(.060)$ & $79.990(33.047)$ & $77.062(10.441)$ \\
\cline { 2 - 6 } & TEL & $13.74(14.189)$ & $.293(.156)$ & $62.759(38.502)$ & $85.232(14.080)$ \\
\cline { 2 - 6 } & OTW & $43.97(18.698)$ & $.275(.075)$ & $131.211(28.777)$ & $79.572(8.189)$ \\
\hline
\end{tabular}


The concept of remote tower operations has been addressed as a suitable solution and is being developed in many countries. This research provided scientific evidence that multiple remote tower operations can achieve the objectives of Single European Sky ATM Research program. For the MRTO validation campaign, simultaneous landing and take-off at both airports are identified as traffic situations that should be examined further to explore the standards of safe operations and acceptable workload to ensure optimum ATCO task performance. During the trials no critical safety issues were identified by the team or other stakeholders such as pilots, or airport vehicles drivers. The trials provide one indication that multiple remote tower operations from an RTM can provide an acceptable level of safety (ALOS). A summary of operational results based on the 50 live exercises of multiple remote tower operations described as follows (table 6).

4.2.1 Batch-1 live trials: The first batch, exercises 1 to exercise 5, focus on Surface Movement Control which is the air traffic control service provided to aircraft, vehicles and personnel on the manoeuvring areas of Cork and Shannon airports excluding the runway in use. In certain cases, the SMC controller may provide an advisory service to aircraft on the aerodrome apron. The first batch of 5 exercises were to familiarize operational and technical personnel with procedures to be used for SMC. There were no safety occurrences in these 5 trials, however there are some human factors issues to be aware of including (1) incorrect selection of a button on the COMPAD; (2) the Out of the Window view operates via a single shared mouse pointer which, from time to time, resulted in one Controller waiting for the other to manoeuvre the Zoom Camera; (3) in a local Tower environment the AMC and SMC can easily monitor each other's activities whereas in this exercise it was more difficult; (4) the working relationship between the SMC and AMC requires more intercom work. It is unlikely that in a future operation the AMC and SMC would be in a different location.

4.2.2 Batch-2 live trials: The second batch comprising exercises 6 to exercise 20 were to demonstrate the applicability of integrating both SMC and AMC with incrementally increasing traffic movements and mixing arrivals and departures at both Cork and Shannon airports. The suitability of the equipment has been assessed with a number of comments. During this phase the simultaneous scenario (Cork and Shannon) was introduced with low traffic movements. There were no safety occurrences in these 15 trials, however there are some potential risks to be aware of including (1) difficulty in seeing small aircraft and rapid climbing aircraft; (2) increased workload as a result of increased simultaneous tasks; (3) the level of service is different to a local tower operations adding pressures to ATCOs; (4) 
distractions due to multiple airports and multiple tasks; (5) quality of services might vary under operational conditions.

4.2.3 Batch-3 live trials: The third batch comprising exercise number 21 to exercise 50 built on the experience gained from previous exercises with increased traffic as appropriate in the sequenced and simultaneous scenarios. MRTO procedures in the previous batches were assessed with no additional procedure changes or amendments being required. However potential changes were discussed to operating methods in any future RTC environment such as better cooperation between airports involved in a Multiple Tower Operation whereby vehicle activity at each airport is coordinated so as to manage the workload of the MRTO controllers. Again, there were no safety occurrences in these 30 trials, however there are some potential risks to be aware of including (1) optimum traffic movements must be determined; (2) contingency plans for single ATCO performing multiple tower operations in the event of ATCO incapacitation for example; (3) set up of CWP in the RTC; (4) understanding the differences between 'in sequence' and 'simultaneously'.

Table 6. Summary of operational exercises based on the 50 live exercises

\begin{tabular}{|c|c|c|}
\hline $\begin{array}{c}\text { Objectives of } \\
\text { Exercises } \\
\end{array}$ & Criteria & Results of Exercise \\
\hline $\begin{array}{l}\text { To evaluate the } \\
\text { human } \\
\text { performance } \\
\text { related to } \\
\text { Human- } \\
\text { Computer } \\
\text { Interaction } \\
\text { (HCI) in a } \\
\text { sequenced or } \\
\text { simultaneous } \\
\text { scenario. }\end{array}$ & $\begin{array}{l}\text { Human performance and } \\
\text { human factors have been } \\
\text { measured and assessed } \\
\text { for 'in sequence' and } \\
\text { 'simultaneous' scenarios }\end{array}$ & $\begin{array}{l}\text { There were two minor HF issues (1) The other } \\
\text { minor issue was the Controller, on one } \\
\text { occasion, made an incorrect selection of a } \\
\text { button on the COMPAD; (2) The Mouse } \\
\text { pointer in the Out of the Window view is a } \\
\text { shared mouse pointer which, from time to } \\
\text { time, resulted in one Controller waiting for the } \\
\text { other to manoeuvre the Zoom Camera. } \\
\text { However, with practice during the trials the } \\
\text { Controllers became adept at co-ordinating the } \\
\text { use of the mouse. }\end{array}$ \\
\hline $\begin{array}{l}\text { 2. To identify } \\
\text { shortcomings } \\
\text { and limitations } \\
\text { in order to } \\
\text { identify } \\
\text { corrective } \\
\text { actions } \\
\text { required before } \\
\text { next batch of } \\
\text { exercises }\end{array}$ & $\begin{array}{l}\text { Any shortcomings and } \\
\text { limitations have been } \\
\text { identified and assessed } \\
\text { and detailed for further } \\
\text { examination. }\end{array}$ & $\begin{array}{l}\text { In local Tower the AMC and SMC can easily } \\
\text { monitor each other's activities whereas in this } \\
\text { exercise it was more difficult. This presented a } \\
\text { change in the working relationship between the } \\
\text { SMC and AMC in terms of more intercom } \\
\text { work was required. It is unlikely that in a } \\
\text { future operation the AMC and SMC would be } \\
\text { in a different location. However more } \\
\text { evaluation would be required on this impact if } \\
\text { this was to become the normal situation. }\end{array}$ \\
\hline $\begin{array}{l}\text { 3. To demonstrate } \\
\text { that the full } \\
\text { range of ATS } \\
\text { as provided } \\
\text { from on-site } \\
\text { control towers } \\
\text { can be } \\
\text { provided } \\
\text { without }\end{array}$ & $\begin{array}{l}\text { The tasks and duties of } \\
\text { the ATCO providing } \\
\text { services from the RTC } \\
\text { have been measured and } \\
\text { assessed in line with the } \\
\text { developed procedures to } \\
\text { ensure that there was no } \\
\text { degradation of service } \\
\text { when providing a }\end{array}$ & $\begin{array}{l}\text { As observed in the exercises } 6 \text { to } 20 \text { there are } \\
\text { obvious differences between the Local Tower } \\
\text { Operation and the RTC Operation. This mainly } \\
\text { relates to the fact that the view from the Local } \\
\text { Tower is better than the RTC. Some examples } \\
\text { of this are: In exercise } 10 \text {, the EFS is a } \\
\text { fantastic tool with measurable safety benefits } \\
\text { that the current paper strips don't provide. In } \\
\text { exercise } 15 \text { there is a discussion about the }\end{array}$ \\
\hline
\end{tabular}




\begin{tabular}{|c|c|c|c|}
\hline & $\begin{array}{l}\text { degradation } \\
\text { from the RTC }\end{array}$ & service from the RTC. & $\begin{array}{l}\text { difficulty in seeing smaller aircraft. In exercise } \\
16 \text { there is a discussion about rapid climbing } \\
\text { aircraft. In exercise } 17 \text { there is a discussion } \\
\text { about challenging lighting conditions. }\end{array}$ \\
\hline 4. & $\begin{array}{l}\text { To evaluate the } \\
\text { human } \\
\text { performance } \\
\text { from the } \\
\text { ATCO's and } \\
\text { other human } \\
\text { operators } \\
\text { perspective in a } \\
\text { sequenced or } \\
\text { simultaneous } \\
\text { scenario. }\end{array}$ & $\begin{array}{l}\text { Human performance and } \\
\text { human factors have been } \\
\text { measured and assessed } \\
\text { for 'in sequence' and } \\
\text { 'simultaneous' scenarios } \\
\text { related to attention } \\
\text { distributions, situation } \\
\text { awareness and perceived } \\
\text { workload during } \\
\text { performing multiple } \\
\text { remote tower operations }\end{array}$ & $\begin{array}{l}\text { Controllers are conscious of the fact that due to } \\
\text { multiple tasks having to be done at the same } \\
\text { time that the level of service is not the same as } \\
\text { in the Local Tower and this adds to the } \\
\text { pressure on the RTC ATCO. The main reason } \\
\text { for this is that the Controller knows that if he } \\
\text { was just performing a task for a single airport } \\
\text { that e.g. this Vehicle would not have been } \\
\text { delayed but because he was engaged in another } \\
\text { task for the other airport he is delaying } \\
\text { something in the other airport. This is alien to } \\
\text { the Controllers because they would be used to } \\
\text { very rarely having to delay replying to a } \\
\text { Vehicle when Operating in the Local Tower. }\end{array}$ \\
\hline 5. & $\begin{array}{l}\text { To demonstrate } \\
\text { the state of } \\
\text { readiness of the } \\
\text { remote tower } \\
\text { initiative for } \\
\text { industrialisatio } \\
\mathrm{n} \text { in the case of } \\
\text { ATS provision } \\
\text { for multiple } \\
\text { airports }\end{array}$ & $\begin{array}{l}\text { An assessment of the } \\
\text { live trial demonstrations } \\
\text { to support the proof of } \\
\text { concept and readiness } \\
\text { for industrialisation of } \\
\text { remote towers for } \\
\text { multiple airports has } \\
\text { been conducted and } \\
\text { assessed as positive. }\end{array}$ & $\begin{array}{l}\text { The document "LSD } 0204 \text { IAA Remote } \\
\text { Tower System Operational Evaluation" } \\
\text { (Annex } 3 \text { to this report) provides the project } \\
\text { teams full assessment of the state of readiness } \\
\text { of the systems provided for the provision of } \\
\text { ATS provision for multiple airports. The } \\
\text { document lists a number of suggestions for } \\
\text { changes to systems which should be } \\
\text { considered in advance of any potential future } \\
\text { deployment. }\end{array}$ \\
\hline 6. & $\begin{array}{l}\text { To assess the } \\
\text { demonstration } \\
\text { exercises with } \\
\text { respect to } \\
\text { sequencing and } \\
\text { metering to } \\
\text { support 'in } \\
\text { sequence' and } \\
\text { 'simultaneous' } \\
\text { operations. }\end{array}$ & $\begin{array}{l}\text { The application of } \\
\text { sequencing and metering } \\
\text { processes as applied to } \\
\text { two airports was } \\
\text { measured and assessed. }\end{array}$ & $\begin{array}{l}\text { As outlined in Batch } 3 \text { the project team have } \\
\text { gained a very good understanding of what is } \\
\text { possible in a Multiple airport 'in sequence' and } \\
\text { 'simultaneous' aircraft operations. The new } \\
\text { technology of PTZ, OTW and EFS did } \\
\text { facilitate ATCOs task performance on multiple } \\
\text { remote tower operations (exercises } 46,47,48 \text { ). }\end{array}$ \\
\hline
\end{tabular}

\section{Discussion of Large Scale Demonstration (LSD)}

The emergence of multiple remote tower operations is due in part to the changing operational environment in air transportation which had rapid expansion by low cost carriers at smaller airports. Cost constraints required ANSPs to develop new concepts and new technologies to fit the new business environment. The management of incoming and outgoing traffic at airports is a major function of ATCOs who follow procedures and guidance established by past practice, industry guidelines and regulatory policies. The operational procedures seek to ensure the safety while enabling efficiency operations (MacLean, Richman, \& MacLean, 2016). The demonstration of 50 live trial exercises represented real-time, dynamic air traffic 
operations at both Cork and Shannon airports and demonstrated multiple remote tower operations had no degradation in safety levels, no negative impact on capacity and human performance (European Aviation Safety Agency, 2015a; SESAR Joint Undertaking, 2013). Based on the results of these trials, the visual target tracking design of remote tower systems enables the automatic tracking moving objects such as vehicles/persons/animals on the manoeuvring area and aircraft in the air. This new technology has contributed to improved visual acquisition and has improved ATCOs' situational awareness.

\subsection{New Technology Induced Unexpected Visual Behaviours related to HCI}

It was observed that depth perception was a potential issue (exercises 15, 16 \& 17) in the RTC, as it was easier to judge the position of an aircraft in relation to another aircraft from the local tower than the RTC (Howard, 2012). When a single controller is responsible for four tower roles $\mathrm{AMC} / \mathrm{SMC}$ in two airports, there is a requirement to actively use four frequencies in addition to monitoring two separate approach unit frequencies (for situational awareness). Consequently, there is an increased likelihood of the controller missing a transmission by an aircraft or vehicle (Bailey, Konstan, \& Carlis, 2001). The organisation of whole communications systems in an RTC needs to be explored further regarding Human-Computer Interactions with EFS, RDP, OTW and TEL impacting to ATCO's visual response, auditory response, spoken response, manual response and cognitive processing information.

The visual presentation of remote tower system in relation to the HCI functions shall not exceed the 1,000 millisecond of end-to-end delay in order to fit the requirements of safety assessment (European Aviation Safety Agency, 2015a). The results of eye tracking data analysis demonstrated the average fixation durations on OTW (275 ms), EFS (232 ms) and RDP (269 ms) for the scenario of aircraft in sequence departing and landing to Cork (table 5). The relationship of human information processing and complexity of operational tasks are related to the length of fixation duration (K. Rayner, 1998; Singh \& Singh, 2012). The fixation duration is related to the amount of information processing (K. Rayner, 1998; Singh \& Singh, 2012). When a single controller is managing two simultaneous arrivals into two different airports, EFS is the shortest fixation duration (232 ms), it may be the contribution of the comprehensive interface design. On the other side, the long fixation duration is on the TEL (293ms) which might be due to the complicated operational requirement to monitor so many radio frequencies at two airports. Furthermore, saccade is defined as fast eye movement between fixations and generally it declines as a function of increased mental workload (Ahlstrom \& Friedman-Berg, 2006). The results reveal that saccade amplitude has significant 
interaction between AOIs and tasks performance. The TEL display consists of a screen with buttons and small digital numbers of radio frequencies used by all moving aircraft, vehicles and other parties on both Cork and Shannon airports. ATCO's must pay attention to select the correct frequency to communicate safely.

The view of OTW displays objects at a smaller size compared to the object size when viewed from the Local Tower, this results in it being difficult to see smaller objects far away from the camera. For areas of the airfield such as runway incursion hotspots further than $1.5 \mathrm{KM}$ from the cameras continuous use of the PTZ is required to get a clear view of the area. When two controllers were working in the RTC, as AMC or SMC controllers, at times both controllers required the use of the PTZ, due to current system design simultaneous interaction with another different PTZ was not possible and created a situation where one controller was not able to use PTZ. The interaction with PTZ and EFS (figure 6) is a new HCI issue which and might increase workload for ATCOs, an induced workload by MRTO which does not exist in Local Towers to the same extent, i.e. PTZ is used more frequently than binoculars (Marchitto, Benedetto, Baccino, \& Canas, 2016). In order to try to mitigate and reduce this workload in future MRTO, the IAA had discussed system revisions on PTZ manipulation with the supplier including: (1) Automatic PTZ tracking of certain Objects as determined by the controller; (2) Explore HMI adjustments to the PTZ manipulation; (3) Hotspot Cameras set up on targeted distant areas of the airfield displayed permanently on separate displays.

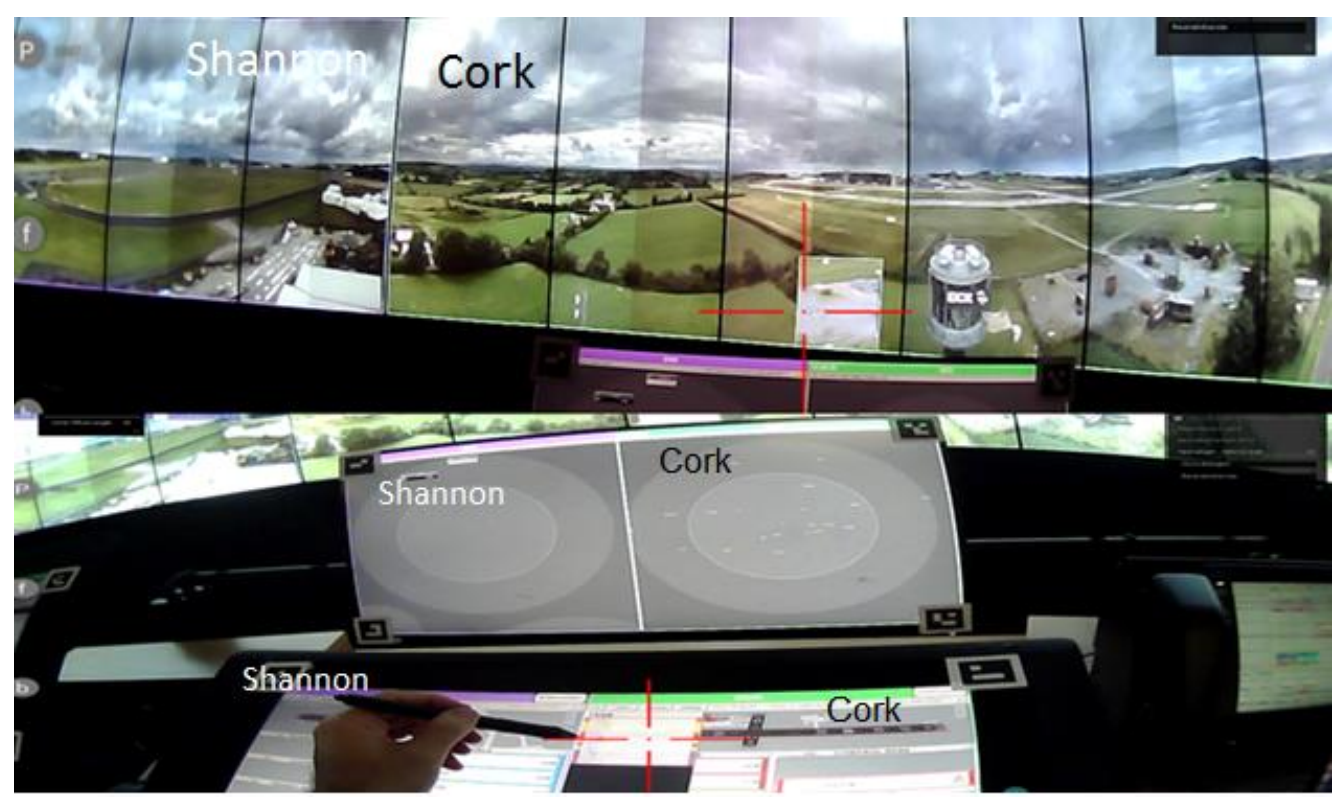

Figure 6. ATCO's fixation duration on the EFS and OTW with PTZ recorded by Eye Tracker to investigate HCI functions and Human Performance on RTM 


\subsection{Impact on Safety}

The certification of Innovative remote tower systems has to evaluate human information processing at initial operational stage to assure improved operators' situation awareness, and safety (Satterfield, McCauley, Caldwell, \& Dongen, 2016). To conduct live exercises of multiple remote tower operations, the safety case has to be approved by regulators. The IAA mandated a fundamental principle which required that MRTO operations must maintain at least the same level of safety of operations as that which local tower operation provides. The safety case provided the evidence, arguments and assumptions to support this principle. During the trials the air traffic controllers and the RTC project team were governed by the same safety management policies, principles and procedures that exist in the Local Tower operations. Tower controllers are responsible for the safety and efficiency of the air movements and ground movements. Therefore, the monitoring of traffic within the control zone by ATCO's visual attention resources is an important safety mechanism (Papenfuss \& Friedrich, 2016). There were no safety occurrences during the 50 live exercises where there was a reduction in safety barriers which was not anticipated or provided for during the Safety Case development and update. When an AMC is managing two simultaneous arrivals into two different airports, ideally the first landing aircraft should be stable on the runway before the second arrival aircraft is 1NM from touchdown at the other aerodrome. However, OTW has the longest fixation duration for SMC due to the complexity of aircraft and vehicle movements. A Single ATCO performing simultaneous AMC and SMC functions is the biggest challenge within MRTO, as RDP and OTW show long fixation durations on multiple tasks.

To ensure the safety of operations by a single ATCO performing simultaneous departures at two different airports, it is suggested that additional time and distance between aircraft cleared for take-off and landing is implemented. This is because it is good practice that ATCOs monitor the critical phases of aircraft flight during initial roll and rotation and during the landing and rollout. There is a need to conduct further investigation of ATCO's visual attention related to situation awareness and HCI in the future. The project team concluded therefore that there was no adverse impact on safety while conducting the Remote Tower Trials from the RTC and conditions for the grant of project acceptance by the NSA were successfully maintained. The live trial exercises demonstrated that the ATS provided by the RTC for a single airport and two medium airports by a single controller with 'in sequence' and 'simultaneous' aircraft operation was at least as safe as the ATS provided by the Local Towers at both Cork and Shannon aerodromes. No safety occurrence was reported nor did any 
operational safety issue arise during the conduct of the fifty live trial exercises. Based on the live exercises as per the demonstration Plan, the objective of no degradation in safety levels between remote and local tower operations was achieved.

\subsection{Impact on Capacity}

In advance of commencing the Remote Tower trials, it was agreed that there would be little or no change to, or deviation from the air traffic services that the aircraft operators would normally experience when these services were provided from the Local Towers. In addition, when the RTC had control of the Shannon and Cork AMC positions, predicted traffic was constantly monitored to determine if and when the two AMC positions could be merged. On occasion when the two AMC positions were merged and controlled by a single controller it was necessary to ensure that ATCO didn't suffer from high workload and consequently impact safety and capacity. The control of a single Local Tower with both SMC and AMC positions from an RTC was applicable for the levels of traffic in the exercise scenarios. In advance of the positions being combined there were seven scheduled arrivals to the two airports in addition to a number of VFR aircraft. This situation initially increased ATCO's workload when operating AMC for two airports. Although the benefit of remote tower provision of ATC services for multiple remote towers was predicted to increase efficiency by $60 \%$ at some locations (Ziegler, 2016), it might have trade-off effects through increased ATCO's perceived workload when performing multiple tasks. Exercise-32 demonstrated that two 'in sequence' arrival flights into the two airports were manageable but it was noted that there was potential for delay at one airport due to activities at the other airport, particularly if that activities are unexpected or non-routine. The measurement of pupil dilation has been used to investigate the status of cognitive processes and mental workload, as pupil diameter increases as an indication of cognitive demand (Ahlstrom \& Friedman-Berg, 2006). The results revealed that TEL is the highest pupil dilation (85.23 pixels), followed by RDP (81.46 pixels), OTW (79.57 pixels) and EFS (77.06 pixels). The controller managed his workload in the exercise and was able to prioritise which work had to be done and which work could wait while interacted with RTM (Kearney, Li, \& Lin, 2016).

Operating innovative technology of RTM to maintain safe separation of aircraft both in the air and on the ground is not only an issue of technical skill performance but also of real-time decision-making involving situation awareness and risk management within a time-limited environment ( $\mathrm{Li}, 2011)$. There may be a time lag based with MRTO compared to Local 
Tower operations, due to low cloud and moisture impacting the cameras and not impacting the Local Tower. For future application, workload resilience must be monitored to ensure that unplanned, unexpected aircraft such as Search and Rescue Helicopters can be accommodated without delay. Based on the exercises in the Demonstration Plan, there was no significant negative impact on capacity on multiple remote tower operations (table 7).

Table 7: The summary of Demonstration Plan of live exercises reflect to Capacity

\begin{tabular}{|c|c|}
\hline Leading organization & Irish Aviation Authority \\
\hline Demonstration exercise objectives & $\begin{array}{l}\text { The High level objective is to verify: } \\
\text { - System Capability \& Suitability } \\
\text { - Operational CONOPS \& Procedures Fine Tuning } \\
\text { - Measurements for "In Sequence" Operations } \\
\text { - } \\
\text { - Initial measurements for "Simultaneous" Operations }\end{array}$ \\
\hline $\begin{array}{l}\text { High-level description of the Concept of } \\
\text { Operations }\end{array}$ & $\begin{array}{l}\text { These exercises will introduce aircraft in the air controlled } \\
\text { by AMC at the RTC for the two airports. } \\
\text { The AMC will be done by the RTC for both airports. } \\
\text { The SMC will control the ground traffic at both airports. }\end{array}$ \\
\hline Applicable Operational Context & $\begin{array}{l}\text { - } \quad \text { Cork \& Shannon airport } \\
\text { - All SMC (Surface Movements OPS) } \\
\text { - All Aircraft controlled by AMC at the RTC for both } \\
\text { airports in light traffic i.e. }<3 \text { aircraft for both } \\
\text { airports. } \\
\text { - Perform initial analysis on other influencing factors } \\
\text { such as Daylight \& poor weather conditions. }\end{array}$ \\
\hline Impact on Capacity & $\begin{array}{l}\text { Capacity: No negative impact on Capacity or traffic that can } \\
\text { be handled in this mode. } \\
\text { Cost efficiency: Document initial results for a single ATCO } \\
\text { performing the task which today is performed by two } \\
\text { ATCOs }\end{array}$ \\
\hline
\end{tabular}

\subsection{Impact on Human Performance}

Air traffic control is a complex cognitive task, it involves perceived information, processing information and decision-making (Papenfuss \& Friedrich, 2016). During the trials a number of human factor issues were encountered, most of which were anticipated (e.g. the operation of new equipment and associated HCI) and some which were not anticipated such as the level of noise in the RTC when a single controller was operating four frequencies and monitoring an additional two frequencies. Multiple Remote Tower Operations might be a good solution for increasing safety and capacity of ATS at small/medium airports. There was a trend of increasing ATCO's performance with by-products of also increasing workload on multiple remote tower operations compared to local tower operations. Current research supports previous findings that ATCO mental effort increased and detection performance deteriorated with the numbers of controlled airports (Oehme, Leitner \& Wittbrodt, 2013). There is a 
requirement to address the issue of controllers' perceived workload while performing MRTO either by training, additional staffing or designing new standard operating procedures or interface design (European Aviation Safety Agency, 2015c; SESAR Joint Undertaking, 2013, 2015b), as workload can negatively affect a controller's situation awareness and increase the potential for error. However, suitable human-cantered design RTM including OTW, EFS \& PTZ systems can significantly improve controllers' situation awareness and reduce their cognitive workload (Laois \& Giannacourou, 1995; Tobaruela et al., 2014), and increase their capability to process the information (Wickens, Miller, \& Tham, 1996). Ideally the first landing aircraft should be steady on the Runway before the second arrival aircraft is 1NM from touchdown at the other aerodrome in Multiple Airport Simultaneous Operations (MASO). It was noted that meeting this guideline may be difficult when controlling aircraft of varying approach speeds. Recommendation in this area in the future may be supported by an additional caveat which would give the controller the authority to exercise professional judgement with regard to the issuance of a landing clearance to the second arriving aircraft. Previous research had demonstrated that significant benefits were achievable by the field trials (Simaiakis, Khadilkar, Balakrishnan, Reynolds, \& Hansman, 2014).

A framework of situation awareness based on information-processing model which proposed situation awareness as 'the perception of the elements in the environment within a volume of time and space, the comprehension of their meaning, and the projection of their status in the future' related to task performance (Endsley, 1995). ATCO's visual behaviours provide an opportunity to investigate the relationship between eye movement patterns and task performance. Eye scan pattern is one of the most powerful methods for assessing human beings' cognitive processes (Ahlstrom \& Friedman-Berg, 2006). The air traffic flows of Cork and Shannon were combined in a data set describing traffic situation, consisting of time, type of event and time distance. Only data sets with time distances less than 60 seconds were regarded as valid 'simultaneously' condition. Whilst the landing is represented in the flight movement data by a single timestamp, the actual process of landing occupies the ATCO's attention longer by monitoring closely the final approach until the aircraft touches down and stabilises on the runway. Therefore, two aircraft landing within the 60 second time span can be considered as simultaneous in respect of the monitoring task of the controller (Schier, Papenfuss, Lorenz, Walther, \& Moehlenbrink, 2011). Based on the exercises of Demonstration Plan, there was no negative impact on human performance on multiple remote tower operations. 


\section{Conclusion and Recommendation}

The implementation of multiple remote tower operations is promising as new technologies can assist ATCO situation awareness. The findings are valuable for both ATCO training and system design. In terms of standardisation, the results of the 50 live demonstrations can provide feedback to EUROCAE WG-100 "Remote and Virtual Towers" (EUROCAE, 2016) in developing standards for both single and multiple modes of remote towers systems for adoption by ICAO as standards and recommended practices. There were no safety occurrence reports nor did any operational safety issue arise during the conduct of the fifty live trial exercises. However, there are some issues to be aware of for future implementation, including the impact of monitoring different radio frequencies and perceived workload. Workload management in the provision of ATS for multiple towers is a new challenge for air traffic controllers, and practice is required to balance the workload by distributing tasks more evenly where possible. Multiple remote tower operations show potential as an alternative to traditional Local Towers. The novelty and flexibility of the advanced technology allows regulators to be creative in adapting operations to fit safety regulations, it also has the potential to fundamentally change the way operators provide ATS. From a regulatory perspective the results of these live trials may contribute to EASA rulemaking activity for single and multiple airports remote tower operations.

\section{Acknowledgements}

The authors would like to express special thanks to Peter Kavanagh, IAA Manager Operational Support Group; and Gerald Caffrey, Manager Support Co-ordination, and all Air Traffic Controllers contributing to this project. Their support and the enthusiasm of their respective teams were invaluable in facilitating the authors' research efforts.

\section{Funding:}

This work was supported by Single European Sky ATM Research Program (SESAR, LSD 02.04), and the Irish Aviation Authority (P7883/ETE/WCL). Also, this project had received the award of European Commission entitled the 2017 Single European Sky Award of “Performance - Cost Efficiency: Multiple Tower Operations by Single ATCO”.

\section{References}

Ahlstrom, U., \& Friedman-Berg, F. J. (2006). Using eye movement activity as a correlate of 
cognitive workload. International Journal of Industrial Ergonomics, 36(7), 623-636. doi:10.1016/j.ergon.2006.04.002

Bailey, B. P., Konstan, J. A., \& Carlis, J. V. (2001). The effects of interruptions on task performance, annoyance, and anxiety in the user interface. Paper presented at the Human-Computer Interaction - Interact'01, Tokyo, Japan.

Dorighi, N., \& Rabin, B. (2002). ASA sses virtual reality to target runway incursions at LAX. Paper presented at the FAA Technology Transfer Conference.

Ellis, S. R., \& Liston, D. B. (2016). Visual features used by airport tower controllers: Some implications for the design of remote or virtual towers. In N. Furstenau (Ed.), Virtual and Remote Control Tower: Research, Design, Development and Validation (pp. 2151). Springer Nature, Switzerland: Furstenau, N.

Endsley, M. R. (1995). Measurement of situation awareness in dynamic systems. Human Factors, 37(1), 65-84. doi:10.1518/001872095779049499

EUROCAE. (2016). Working group 100 - Developing european standards for remote and virtual towers ED-240.

European Aviation Safety Agency. (2014). Term of reference for a rulemaking task: Technical requirements for remote tower operations.

European Aviation Safety Agency. (2015a). Guidance material on the implementation of the remote tower concept for single mode of operation.

European Aviation Safety Agency. (2015b). Notice of proposed amendment 2015-04: Technical and operational requirements for remote tower operations.

European Aviation Safety Agency. (2015c). Requirements on air traffic controller licensing regarding remote tower operations.

Fürstenau, N. (2016). Model-based analysis of two-alternative decision errors in a videopanorama-based remote tower work position. In N. Furstenau (Ed.), Virtual and Remote Control Tower: Research, Design, Development and Validation (pp. 241-260). Switzerland: Springer Nature.

Federal Aviation Administration. (2012). Airport traffic control tower alternatives. Fort Collins.

Friedrich, M. (2016). Which Metrics Provide the Insight Needed? A Selection of Remote Tower Evaluation Metrics to Support a Remote Tower Operation Concept Validation. In N. Furstenau (Ed.), Virtual and Remote Control Tower: Research, Design, Development and Validation (pp. 221-240). Switzerland: Springer Nature.

Friedrich, M., \& Mohlenbrink, C. (2013). Which data provide the best insight? A field trial for validating a remote tower operation concept. Paper presented at the 10th USA-Europe Air Traffic Management Research and Development Seminar, Chicago, USA.

Hollan, J., Hutchins, E., \& Kirsh, D. (2000). Distributed cognition: Toward a new foundation for human-computer interaction research. ACM Transactions on Computer-Human Interaction (TOCHI), 7(2), 174-196. https://doi.org/10.1145/353485.353487 
Howard, I. P. (2012). Perceiving in depth, volume 1: Basic mechanisms. New York: Oxford University Press. https://doi.org/10.1093/acprof:oso/9780199764143.001.0001

Kassner, M., Patera, W., \& Bulling, A. (2014). Pupil: An open source platform for pervasive eye tracking and mobile gaze-based interaction. Paper presented at the 2014 ACM international joint conference on pervasive and ubiquitous computing: Adjunct publication, Seattle, WA. https://doi.org/10.1145/2638728.2641695

Kearney, P., Li, W. C., \& Lin, J. J. H. (2016). The impact of alerting design on air traffic controllers' response to conflict detection and resolution. International Journal of Industrial Ergonomics, 56, 51-58. doi:10.1016/j.ergon.2016.09.002

Kraiss, K., \& Kuhlen, T. (1996). Virtual reality: Principles and applications. In N. Furstenau (Ed.), From Sensors to Situation Awareness. DLR-Mitteilung.

Laois, L., \& Giannacourou, M. (1995). Perceived effects of advanced ATC functions on human activities: Results of a survey on controllers and experts. Paper presented at the Proceedings of the Eighth International Symposium on Aviation Psychology, Ohio.

Leitner, R., \& Oehme, A. (2016). Planning remote multi-airport control- Design and evaluation of a controller-friendly assistance system. In N. Furstenau (Ed.), Virtual and Remote Control Tower: Research, Design, Development and Validation (pp. 139160). Springer Nature, Switzerland. https://link.springer.com/content/pdf/10.1007\%2F978-3-319-28719-5_7.pdf

Li, W. C. (2011). The casual factors of aviation accidents related to decision errorsin the cockpit by system approach. Journal of Aeronautics, Astronautics and Aviation, 43(3), 147-154.

Lockwood, S. M., Dorighi, N., Rabin, B., Field, M., \& Madson, M. D. (2002). AIAA 20025811 RUNWAY INCURSION STUDIES IN NASA 'S FUTURE FLIGHT CENTRAL. October, (October), 1-10. https://doi.org/doi:10.2514/6.2002-5811

MacLean, L., Richman, A., \& MacLean, S. (2016). Benchmarking airports with specific safety performance measures. Transportation Research Part A: Policy and Practice, 92, 349-364. doi:10.1016/j.tra.2016.06.016

Marchitto, M., Benedetto, S., Baccino, T., \& Canas, J. J. (2016). Air traffic control: Ocular metrics reflect cognitive complexity. International Journal of Industrial Ergonomics, 54, 120-130. doi:10.1016/j.ergon.2016.05.010

Moehlenbrink, C., \& Papenfuss, A. (2011). ATC-monitoring when one controller operates two airports research for remote tower centres. Paper presented at the Proceedings of the Human Factors and Ergonomics Society Annual Meeting. https://doi.org/10.1177/1071181311551014

Nene, V. A. (2008). A proposed operational concept for nextgen tower. Mitre Corp, Bedford: Mass.

Nickelson, M., Jones, S., \& Zimmerman, T. (2011). Staffed nextgen tower human-in-the-loop simulation. 
Oehme, A., Leitner, R. \& Wittbrodt, N. (2003). Challenges of Multiple Airport ControlExperimental Investigation of a Multiple Airport Control Concept. Aviation Psychology and Applied Human Factors (2013), 3, pp. 1-8. https://doi.org/10.1027/2192-0923/a000034

Otsby J. (2016) “AVINOR REMOTE TOWERS," in The Remotely Piloted Aircraft Systems and Remote Air Traffic Services Symposium, Stockholm, 2016.

Papenfuss, A., \& Friedrich, M. (2016). Head up only-A design concept to enable multiple remote tower operations. Paper presented at the Digital Avionics Systems Conference (DASC), 2016 IEEE/AIAA 35th. DOI: 10.1109/DASC.2016.7777948

Pellegrini, P., \& Rodriguez, J. (2013). Single european sky and single european railway area: A system level analysis of air and rail transportation. Transportation Research Part A: Policy and Practice, 57, 64-86. doi:10.1016/j.tra.2013.09.004

Schier, S., Papenfuss, A., Lorenz, S., Walther, J., \& Moehlenbrink, C. (2011). An approach to support controller work-place design in a multi-airport environment using fast and real-time simulations. CEAS Aeronautical Journal, 2(1), 185-193. doi:10.1007/s13272-011-0030-8

SESAR Joint Undertaking. (2013). Human performance assessment report of Remote and Virtual Tower. 06-09-03.

SESAR Joint Undertaking. (2015a). Demonstration Report RTO. LSD.02.05.

SESAR Joint Undertaking. (2015b). Multiple remote tower - Safety assessment report for multiple remote tower. OFA06.03.01.

SESAR Joint Undertaking (2016). RACOON Demonstration Report. LSD.02.03.

SESAR Joint Undertaking. (2015b). Multiple remote tower - Safety assessment report for multiple remote tower.

Simaiakis, I., Khadilkar, H., Balakrishnan, H., Reynolds, T. G., \& Hansman, R. J. (2014). Demonstration of reduced airport congestion through pushback rate control. Transportation Research Part A: Policy and Practice, 66, 251-267. doi:10.1016/j.tra.2014.05.014

Tobaruela, G., Schuster, W., Majumdar, A., Ochieng, W. Y., Martinez, L., \& Hendrickx, P. (2014). A method to estimate air traffic controller mental workload based on traffic clearances. Journal of Air Transport Management, 39, 59-71. doi:10.1016/j.jairtraman.2014.04.002

Van Schaik, F. J., Roessingh, J. J., Lindqvist, G., \& Falt, K. (2016). Detection and recognition for remote tower operations. In N. Furstenau (Ed.), Virtual and Remote Control Tower: Research, Design, Development and Validation. Springer Nature, Switzerland: 53-65.

Wickens, C. D., Miller, S., \& Tham, M. P. (1996). The implications of data-link for representing pilot request information on 2D and 3D air traffic control displays. International Journal of Industrial Ergonomics, 18(4), 283-293. doi:10.1016/0169- 
8141(95)00065-8

Ziegler, J. (2016). Cut the cost: How can remote tower and virtual tower solutions improve the efficiency and reduce the rperational costs of ATC services for regional airports? 
2018-06-18

Multiple remote tower for Single

European Sky: The evolution from initial

operational concept to regulatory

approved implementation

Kearney, Peter

Elsevier

Kearney P, Li W-C, Multiple remote tower for Single European Sky: the evolution from initial operational concept to regulatory approved implementation, Transportation Research Part A:

Policy and Practice, Volume 116, Issue October, 2018, pp. 15-30

http://dx.doi.org/10.1016/j.tra.2018.06.005

Downloaded from Cranfield Library Services E-Repository 